\title{
Estudo eletrorretinográfico de visão cromática
}

\author{
Electroretinographic studyof chromatic vision
}

\author{
Daniela Cavalcanti Ferrara de Almeida Cunha ${ }^{1}$ \\ Jan Nora Hokoç 2 \\ Adalmir Morterá Dantas ${ }^{3}$ \\ Haroldo Vieira de Moraes Junior ${ }^{4}$ \\ Antônio Marcos Mello Moraes 5
}

\begin{tabular}{|l|}
\hline RESUMO \\
\hline Objetivo: O objetivo deste estudoé descrever o traçado eletrorretinográfico \\
no gambá sul-americano (Didelphis aurita) obtido com estímulo cromáti- \\
co de comprimento de onda seletivo. O eletrorretinograma é o registro das \\
variações de voltagem nas células retinianas, desencadeadas por estímulo \\
luminoso. O eletrorretinograma representa a atividade elétrica combinada \\
de diferentes células, e sofre variações dependendo da fisiologia retiniana \\
edo método de exame. Métodos: Foram registrados os eletrorretinogramas \\
de seis animais em adaptação ao escuro utilizando filtros cromáticos Kodak \\
Wratten ${ }^{\circledR}$, e registrada a sensibilidade espectral para comprimentos de \\
onda específicos nas faixas de cores do azul, verde, amarelo, laranja e \\
vermelho. Resultados: Os resultados eletrorretinográficos mais consisten- \\
tes foram obtidos quando o animal foi estimulado por faixas espectrais \\
seletivas, ao invés de luz branca; e são consistentes com a curva de \\
absorbância das opsinas descritas em fotorreceptores de marsupiais. \\
Estudos prévios sugeriram a tricromacia dos marsupiais por microespec- \\
trofotometria de opsinas e imuno-histoquímica de retina. Esse fundamento \\
morfológico não tinha demonstração fisiológica eletrorretinográfica, até \\
este estudo. Conclusão: Ogambá sul-americanotem se mostradointeressan- \\
te comoanimal experimental no estudo comparativo da fisiologia visual em \\
mamíferos, especialmente no estudo filogenético da visão cromática. Os \\
marsupiais apresentam um modelo retiniano que superpõe os sistemas \\
fotópico e escotópico; e o gênero Didelphis conserva características \\
encontradas em fósseis do período pleoceno. Portanto, o sistema visual \\
de um marsupial resgata características dos primórdios da evolução dos \\
mamíferos, até o desenvolvimento dos padrões retinianos modernos. \\
\hline
\end{tabular}

Descritores: Percepção de cores; Retina/fisiologia; Eletrorretinografia; Opsina

\section{INTRODUÇÃO}

Nosso conhecimento da visão de cores dos mamíferos está ainda limitado, e é ainda menor sobre mamíferos não-placentários. A maioria das espécies estudadas tem alguma forma de dicromacia baseada nos mecanismos de dois cones. A diferenciação da tricromacia em macacos e no homem é relativamente recente na escala evolutiva, e alguns primatas ainda têm apenas um tipo de cone. Esta simplicidade do estímulo visual de cones em algumas espécies contrasta com a complexidade em outros vertebrados, como pássaros e répteis, de retinas com grande dominância de cones. Ainda hoje, a transição evolutiva até as retinas modernas de mamíferos não está completamente elucidada ${ }^{(1)}$.

Todos os tipos de cones de mamíferos foram considerados isomórficos, até que se demonstrou em marsupiais a presença de uma variedade de cones, incluindo cones duplos e fotorreceptores com gotas de óleo ${ }^{(2)}$. 
Estudos em gambás, incluindo testes comportamentais de discriminação cromática ${ }^{(3)}$ e registros eletrorretinográficos ${ }^{(4)}$ indicam alguma capacidade de visão de cores.

O gambá sul-americano (Didelphis aurita) tem se mostrado interessante como animal experimental no estudo comparativo da fisiologia visual em mamíferos. O gênero Didelphis parece não ter se modificado muito ao longo do tempo, e fósseis do período Pleoceno já mostram características atuais ${ }^{(5)}$. Acredita-se que os marsupiais, assim como os monotremos e mamíferos insetívoros, tenham tido um ancestral comum. Por essa razão, o estudo do sistema visual de um marsupial resgata características dos primórdios da evolução dos mamíferos. Além disso, a retina do gambá compartilha características presentes na retina de répteis e aves, e seu conhecimento sugere possíveis transições sofridas pelo sistema visual ao longo da evolução das espécies, até o aparecimento de padrões retinianos dos mamíferos placentários mo$\operatorname{dernos}^{(6)}$. A diversidade de fotorreceptores, fotopigmentos e gotículas de óleo presentes em répteis e aves podem refletir uma sequiência evolutiva relacionada ao hábito de vida diurno e à visão fotópica. A perda de gotículas de óleo em fotorreceptores de mamíferos placentários parece estar relacionada ao processo de seleção para a visão fotópica e cromática. Os mamíferos primitivos ocuparam nichos com hábitos de vida noturnos, induzindo uma diferenciação e otimização do sistema visual escotópico refletidas principalmente no aumento do número de bastonetes da retina. Comparando-se os sistemas fotópico e escotópico, o gambá apresenta um modelo retiniano que se superpõe aos dois grupos.

O objetivo de nosso estudo é demonstrar a resposta eletrofisiológica da retina do mamífero Didelphis aurita quando estimulada por comprimentos de onda seletivos, correspondentes às faixas de cores dispostas ao longo do espectro de luz visível pelo homem.

No homem a opsina dos bastonetes (rodopsina) tem resposta máxima em estímulo luminoso de comprimento de onda ao redor de 500 nanômetros. Os cones em humanos possuem três diferentes fotopigmentos, com absorção máxima de comprimentos de onda em 420, 535 e 565 nanômetros $^{(7)}$.

$\mathrm{Na}$ maioria dos mamíferos, entretanto, estão presentes apenas dois sistemas fotópicos espectrais, que são as bases da visão dicromática um de cones sensíveis a comprimentos de onda curtos, e outro de cones sensíveis a comprimentos de onda médios a longos ${ }^{(4)}$.

Análise com microespectrofotometria determinou a sensibilidade espectral dos fotorreceptores de duas espécies marsupiais australianas, Tarsipes rostratus e Sminthopsis crassicaudata, representativas das duas maiores divisões taxonômicas dos marsupiais. Foram descritos três tipos de fotopigmentos de cone e um de bastonete em cada espécie, sendo a primeira evidência de visão tricromática em outro mamífero além de primatas. Os comprimentos de onda com absorbância máxima das opsinas de cones foram 557, 505 e aproximadamente $350 \mathrm{~nm}$ na primeira espécie; e 535, 509 e aproximadamente $350 \mathrm{~nm}$ na segunda. Os comprimentos de onda com absor- bância máxima dos fotopigmentos de bastonete foram 502 e $512 \mathrm{~nm}$ em cada espécie, respectivamente ${ }^{(3)}$.

Foram descritas na retina do gambá sul-americano (Didelphis aurita) opsinas com diferentes sensibilidades espectrais, determinadas por método imuno-histoquímico, sugerindo a tricromacia neste animal ${ }^{(8)}$. Este fundamento morfológico não tinha demonstração fisiológica registrada por eletrorretinografia, até este estudo.

\section{MÉTODOS}

Foram estudados seis gambás sul-americanos Didelphis aurita, machos e fêmeas adultos, nascidos em cativeiro no biotério do Instituto de Biofísica Carlos Chagas Filho (IBCCF ${ }^{\circ}$ ), do Centro de Ciências da Saúde, UFRJ. O protocolo experimental seguiu as exigências de aprovação da Comissão de Uso de Animais Experimentais do $\mathrm{IBCCF}^{\circ}$.

Os animais foram anestesiados com Ketamina ( $30 \mathrm{mg} / \mathrm{kg}$ de peso) e Xilasina ( $4 \mathrm{mg} / \mathrm{kg}$ de peso), por administração intraperitoneal. A córnea foi anestesiada com colírio de cloridrato de proximetacaína $0,5 \%$ antes do eletrodo ser posicionado. A midríase foi obtida com tropicamida $1 \%$ tópica ocular.

Foi utilizado o estimulador luminoso modelo Neuropack II ${ }^{\circledR}$ da Nihon Kohden ${ }^{\circledR}$, com emissão de flash luminoso de $20 \mathrm{~J}$ de intensidade. A fonte de luz do estimulador luminoso foi posicionada a $10 \mathrm{~cm}$ do olho do animal. Os eletrodos foram dispostos no estroma corneano ("eletrodo de registro"), na pálpebra ("eletrodo de referência") e na fronte do animal ("eletrodo terra") (Figura 1).

O eletrorretinograma foi registrado após 10 minutos de adaptação ao escuro, utilizando-se estímulos em flash de luz branca (luz visível pelo homem, compreendida na faixa entre 400 a $700 \mathrm{~nm}$ ) e flashes nas faixas do espectro eletromagnético correspondentes ao azul, verde, amarelo, laranja e vermelho. Os estímulos cromáticos seletivos foram obtidos com filtros de gelatina (Kodak Wratten Filters ${ }^{\circledR}$ ) para comprimentos de onda em faixas específicas do espectro de luz visível. Foram utilizados os filtros: 47B, 58, 8, 22 e 92.

A significância estatística dos resultados foi determinada através do teste t-Student nas amostras pareadas e através da análise de variância (ANOVA) nas amostras não pareadas, seguidos do pós-teste de Tukey. O valor de "p" menor que 0,05 foi considerado estatisticamente significativo.

\section{RESULTADOS}

Obtivemos os traçados eletrorretinográficos escotópicos do gambá sul-americano (Didelphis aurita) após estimulação com flash de luz branca e flashes nas faixas do espectro eletromagnético correspondentes ao azul, verde, amarelo, laranja e vermelho. Nestes traçados demonstramos ondas reprodutíveis (Anexo 1).

No gambá adaptado ao escuro registramos as ondas $a$ e $b$ 


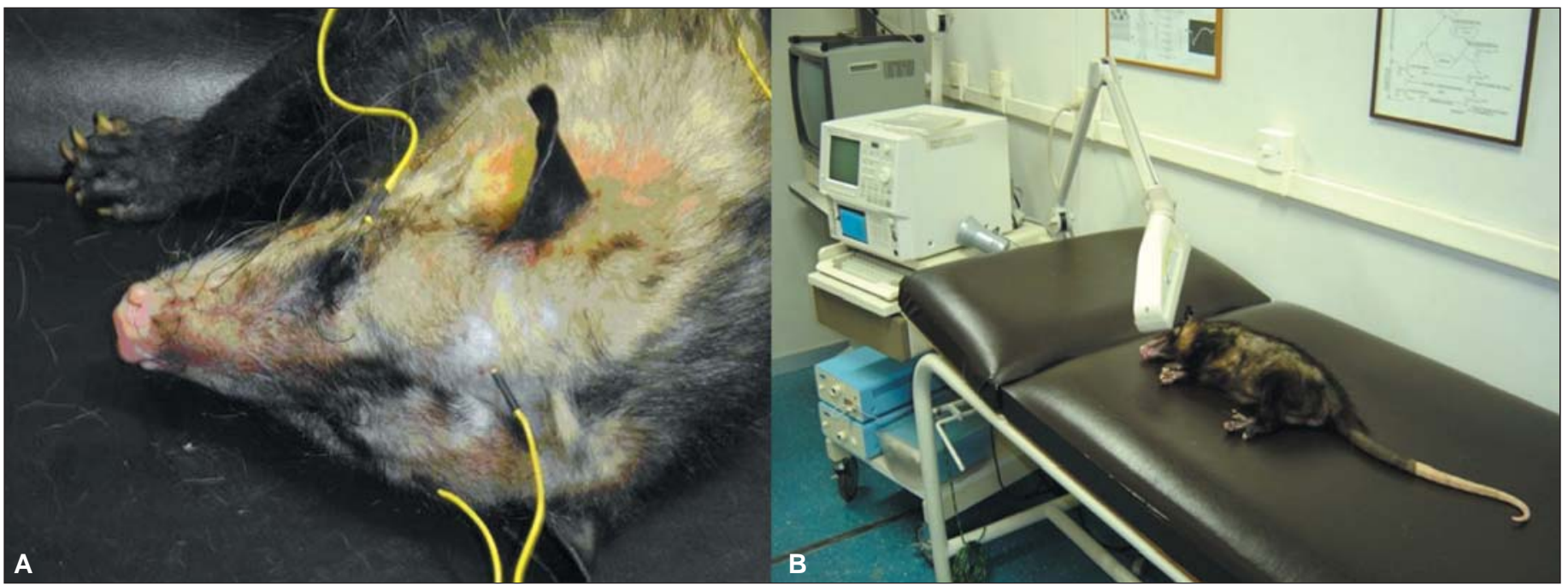

Figura 1 - Método do exame eletrofisiológico no gambá. (A) Animal sob sedação com os eletrodos posicionados e (B) eletrorretinógrafo preparado para exame no Setor de Neuro-Oftalmologia do Serviço de Oftalmologia, Hospital Universitário Clementino Fraga Filho, UFRJ.

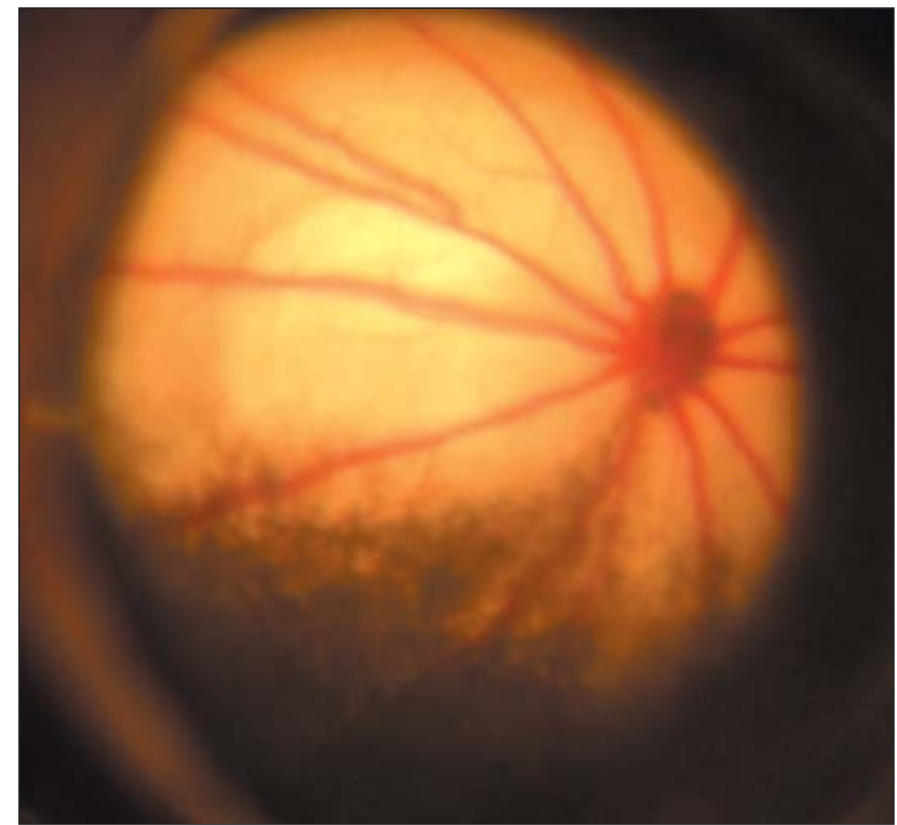

Figura 2 - Retinografia obtida com animal sob sedação

e potenciais oscilatórios típicos do eletrorretinograma, após estimulação luminosa em todas faixas propostas. Em alguns traçados foi possível evidenciar a decomposição das ondas $a$ e $b$ em $a_{1}$ e $a_{2}$, e $b_{1}$ e $b_{2}$.

O eletrorretinograma escotópico não revelou a presença de onda $c$.

No eletrorretinograma fotópico não obtivemos ondas de padrão reprodutível.

Em dois animais estudados as ondas do eletrorretinograma escotópico mostraram-se com pequena amplitude, e foram consideradas subnormais. Um destes gambás foi submetido à sedação com tiopental sódico (30 mg/kg de peso). O outro animal com traçado eletrorretinográfico alterado (subnormal em um olho e abolido em outro) foi posteriormente submetido a oftalmoscopia binocular indireta sob sedação, quando identificamos palidez retiniana severa de etiologia indeterminada.

Foram medidas as seguintes características dos eletrorretinogramas escotópicos obtidos com padrão adequado: amplitude da onda $a$, latência da onda $b$, tempo de culminação da onda $b$ e amplitude da onda $b$.

Analisando-se a amplitude da onda $a$ registrada em cada animal notamos valores consistentes quando o gambá foi estimulado por cada faixa seletiva de comprimentos de onda, com o menor variação de resultado nas faixas de azul e verde. Entretanto, na estimulação pela luz branca os traçados mostraram valores discrepantes de amplitude da onda $a$ entre os animais. A amplitude da onda $a$ foi menor no estímulo na faixa de vermelho do que nos estímulos em outras faixas seletivas, estatisticamente significativa pelo teste t-Student $(\mathrm{p}<0,05)$. Os valores obtidos com estímulo luminoso em faixa de vermelho e em luz branca foram estatisticamente semelhantes $(\mathrm{p}<0,05)$. (Gráfico 1).

Observando-se a amplitude da onda $b$ notamos que os valores registrados em estímulos na faixa do azul e na faixa do verde são os de menor variação. Mais uma vez, os valores obtidos em estímulo de luz branca mostraram a maior variação. Os valores obtidos na medida de amplitude da onda $b$ não mostraram diferença estatisticamente significativa entre os estímulos utilizados, considerando-se o teste de análise de variância $(p>0,05)$ (Gráfico 2).

A latência da onda $b$ mostrou-se constante nos traçados avaliados, principalmente com estímulos de comprimento de onda entre as faixas de verde e amarelo. O estímulo na faixa da cor vermelha resultou nos valores de maior variação. Os valores de latência de $b$ não mostraram diferença estatisticamente significativa entre as faixas seletivas de cores exceto na faixa do 


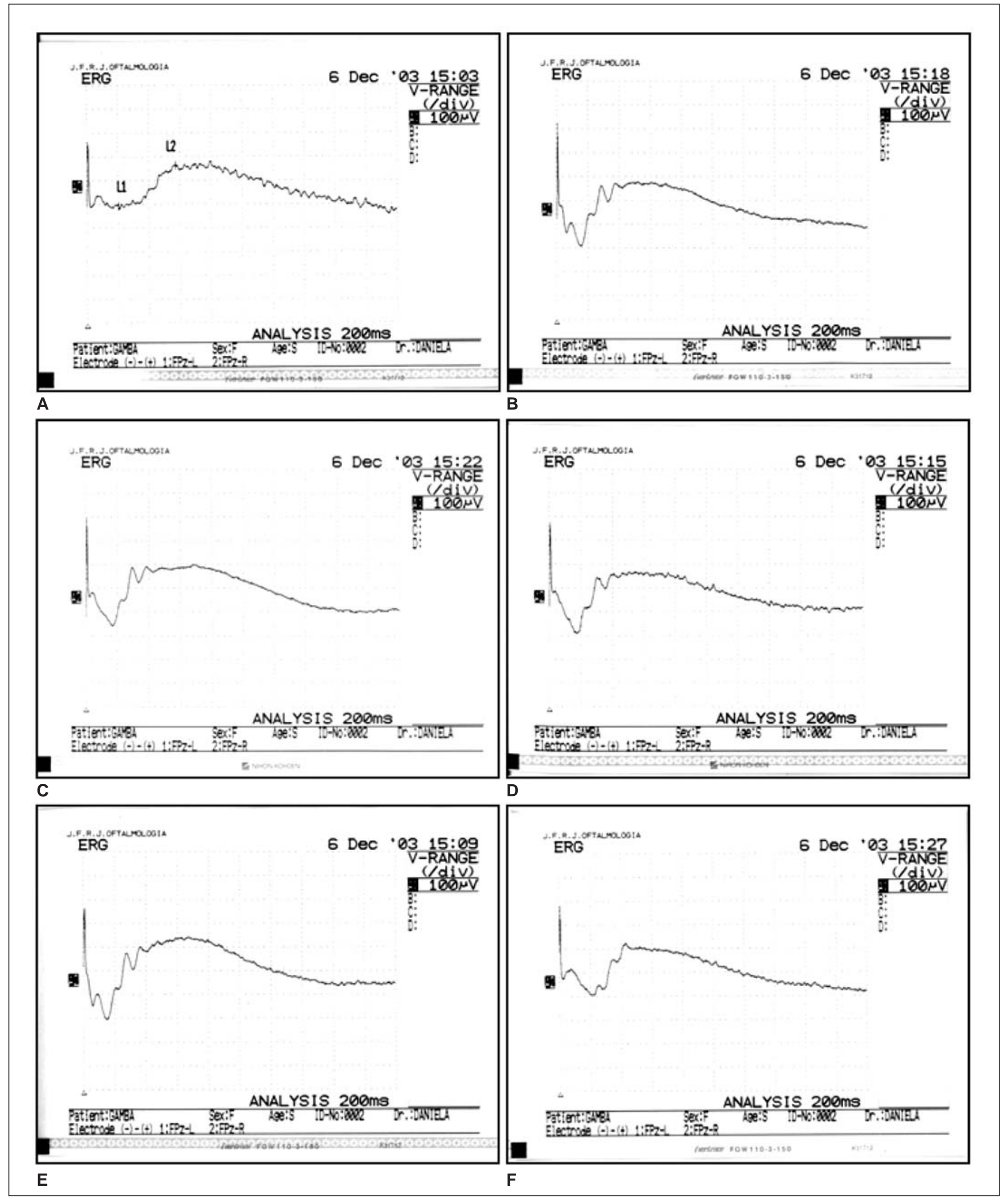

Anexo 1 - Registro eletrorretinográfico. Traçados por estímulo de luz branca (A) e estímulos luminosos nas faixas espectrais de azul (B), verde (C), amarelo (D), laranja (E) e vermelho (F). 
vermelho, que mostrou-se menor em relação às outras faixas seletivas e à luz branca (pelo teste ANOVA, p>0,01) (Gráfico 3).

Da mesma maneira, os estímulos nas faixas de verde e amarelo mostraram a menor variação dos valores do tempo de culminação da onda $b$; enquanto o estímulo luminoso em faixa de laranja mostrou a maior variação. Os valores obtidos não mostraram diferença estatisticamente significativa entre os estímulos de faixas seletivas e de luz branca $(\mathrm{p}>0,05)$; exceto quando comparados os resultados obtidos de estímulos verde e vermelho, quando o verde mostra-se menor (teste ANOVA, p<0,05) (Gráfico 4).

\section{DISCUSSÃO}

Um animal possui visão de cores se é capaz de discriminar

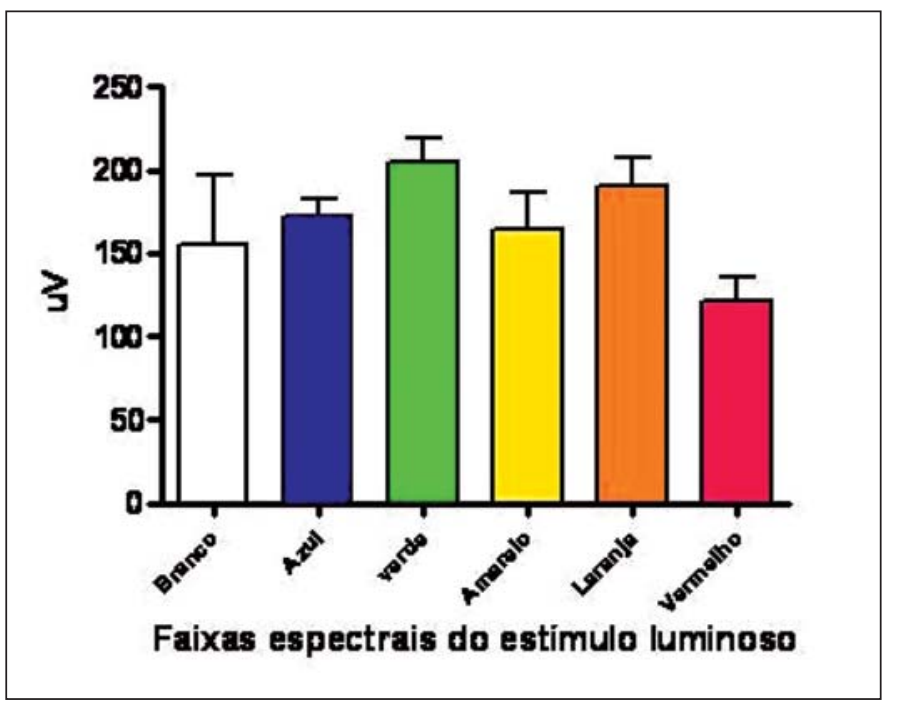

Gráfico 1 - Amplitude da onda a

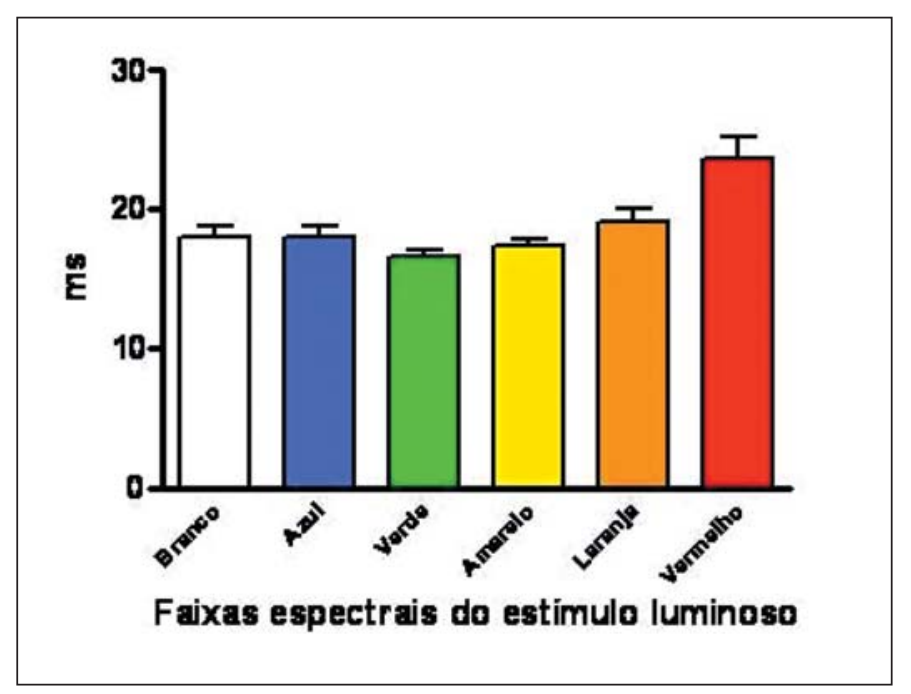

Gráfico 3 - Latência da onda $b$ diferentes estímulos de energia espectral; independentemente da intensidade de contraste dos estímulos. Isto é, considerando-se a percepção, os estímulos devem ser diferenciados com base na saturação, e não no brilho do contraste.

Para garantir a visão de cores, um animal deve ter dois ou mais mecanismos receptores de luz com diferentes sensibilidades espectrais; e um sistema nervoso organizado de forma que possa interpretar esta recepção. Entre os vertebrados, estes critérios são preenchidos por fotorreceptores com fotopigmentos de diferentes sensibilidades espectrais, e por sistema nervoso central que processa o estímulo destes receptores em rede de oposições espectrais. De fato, é tão estreita a ligação entre estes mecanismos e a visão de cores comprovada por testes comportamentais, que a presença de uma ou outra característica em um organismo é geralmente assumida como evidência da visão de cores.

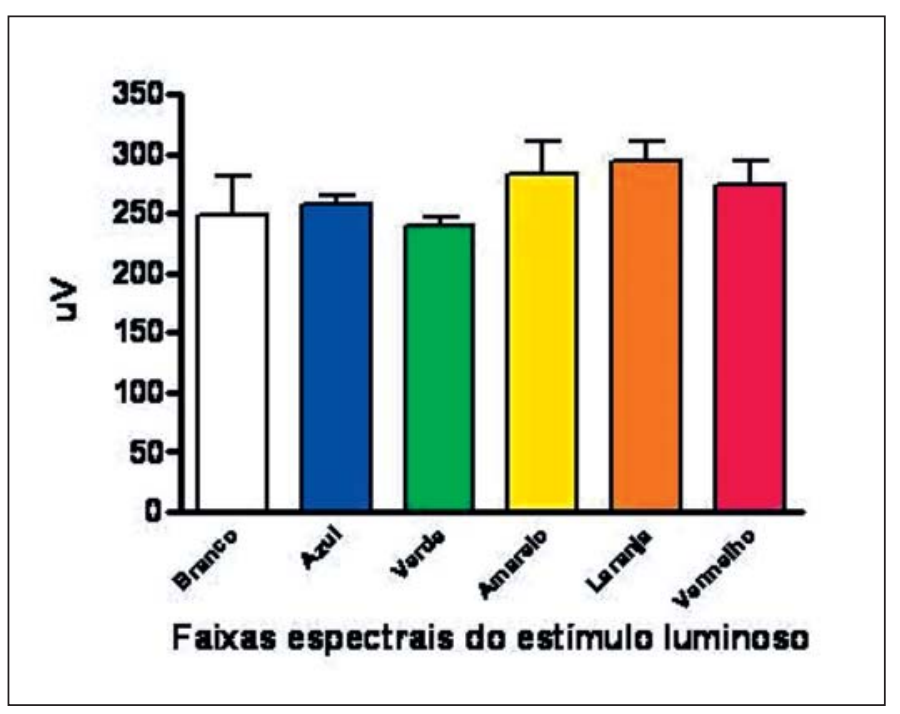

Gráfico 2 - Amplitude da onda $b$

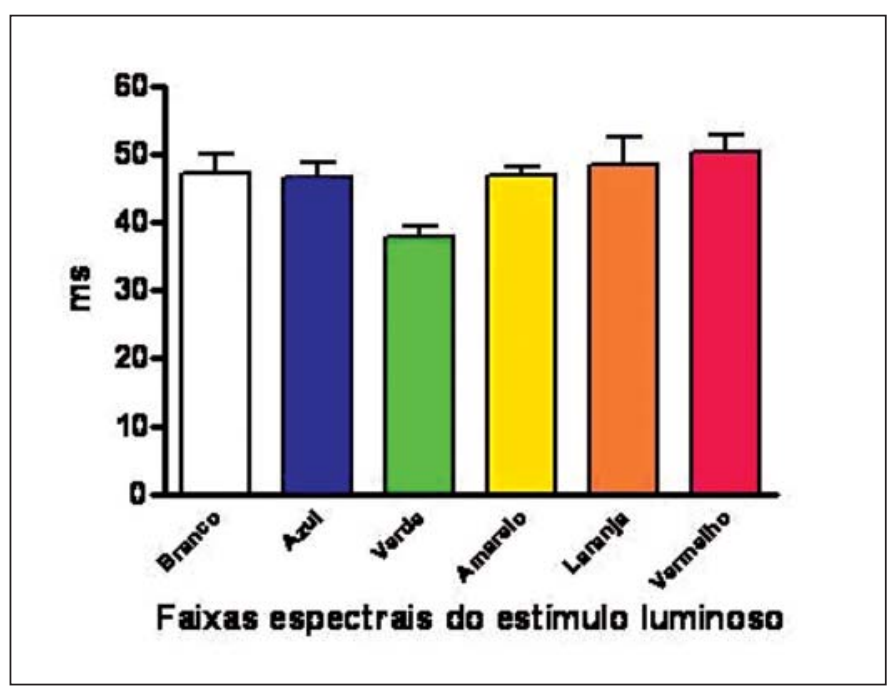

Gráfico 4 - Tempo de culminação da onda $b$ 
Idealmente, um estudo sobre visão de cores deveria ser baseado em evidências diretas de estudos comportamentais corretamente conduzidos. Entretanto, avaliação comportamental da visão de cores em espécie não-humana demanda investimentos substanciais de tempo e dedicação, e ainda assim seus resultados podem ser controversos. Portanto, outras fontes de informação são necessárias, como evidências eletrofisiológicas da função visual.

Outra fonte de estudo sobre visão cromática é a caracterização dos fotopigmentos com a determinação de sua sensibilidade espectral. Muitos experimentos para caracterização de opsinas são desenvolvidos com microespectrofotometria e imuno-histoquímica. Entretanto, a inferência da visão de cores a partir dos tipos de fotopigmentos pode ter algumas limitações. Uma classe de fotopigmento que esteja esparsamente representada no mosaico de receptores pode ser completamente ignorada, tanto por coleta de amostras inadequadas da retina quanto baixa sensibilidade dos métodos de medida ${ }^{(9-10)}$.

Além disso, a correlação entre o número de tipos de fotopigmentos e a dimensão da visão de cores resultante deve ser feita com cautela. A evidência de múltiplos tipos de fotopigmentos na retina não necessariamente resulta na visão de cores. Para que a visão de cores ocorra, estímulo sobre múltiplos tipos de fotopigmentos deve ser contrastado com operações ativas desenvolvidas no sistema nervoso. Aparentemente, isso nem sempre acontece. Existem evidências de que alguns indivíduos têm mais de três tipos de fotopigmentos, e ainda assim estão restritos à visão tricromática. Possivelmente, porque os estímulos resultantes de receptores contendo estes diferentes tipos de pigmento não estão separados no circuito neural ${ }^{(11)}$

Em teoria, seria possível inferir a visão de cores a partir da informação genética de uma espécie. Muitos genes que codificam opsinas de diferentes fotopigmentos foram isolados e seqüenciados. Entretanto, não se determinou exatamente como variações na estrutura primária destes genes estão relacionadas a variações na sensibilidade espectral dos fotopigmentos. Neste caso, deve-se considerar ainda as incertezas adicionais na relação entre o gene e os pigmentos codificados; por exemplo no caso de genes que podem não ser expressos.

Em suma, essas fontes adicionais de informação a respeito da visão de cores são úteis na elaboração de nosso entendimento sobre a visão cromática. Mas devemos direcionar esforços na elucidação de potenciais incertezas na correlação entre os mecanismos visuais neuro-oftalmológicos e a percepção de cores.

\section{CONCLUSÕES}

Observando as amplitudes das ondas $a$ e $b$ concluímos que os traçados de menor variação são obtidos com estímulos nas faixas espectrais de azul e amarelo. Observando os tempos de latência e de culminação da onda $b$ concluímos que os traçados de menor variação são obtidos com estímulos nas faixas de verde e amarelo.

Observando os traçados obtidos com estimulação por luz branca concluímos que este estímulo gera resultados de valores discrepantes, considerando-se as amplitudes das ondas $a$ e $b$. Observando os traçados obtidos por estimulação na faixa espectral de vermelho e laranja, concluímos que com estes estímulos os tempos de latência e de culminação da onda $b$, respectivamente, são muito discrepantes.

Portanto, o estímulo cromático seletivo representa estratégia de exame eletrofisiológico mais adequada do que a estimulação por luz branca. Os traçados eletrorretinográficos mais consistentes foram obtidos quando o animal foi estimulado por faixas espectrais seletivas que correspondem aos comprimentos de onda de maior absorbância das opsinas descritas em fotorreceptores de marsupiais. Portanto, estes resultados oferecem fundamentação fisiológica aos achados histológicos que sugerem a tricromacia de marsupiais.

\section{ABSTRACT}

Purpose: To describe the electroretinogram of the SouthAmerican opossum (Didelphis aurita) obtained by chromatic stimulus of specific wavelengths. The electroretinogram records voltage variations of retinal cells triggered by light stimulation. The electroretinogram represents the combination of electric activity of many different cells and varies according to retinal physiology and examination methods. Methods: We recorded the electroretinogram of six animals in dark adaptation using chromatic Kodak Wratten ${ }^{\circledR}$ filters, and recorded the spectral sensitivity to specific wavelengths in the spectrum of blue, green, yellow, orange and red light bands. Results: The most consistent electrorretinographic results were obtained when the animals were stimulated by selective spectral bands instead of white light. These results are consistent with the absorbance curve of the opsins described in marsupial photoreceptors. Previous studies using microspectrophotometry of opsins and retinal immunohistochemistry suggested marsupial trichromacy. This morphologic knowledge has not before been physiologically demonstrated by electroretinographic methods. Conclusion: The SouthAmerican opossum has proven to be an interesting experimental animal for comparative visual physiology studies among other mammals, especially studies on phylogenetic of chromatic vision. The opossum represents a retinal model that superimposes both the photopic and scotopic systems; and the Didelphis genus shows few changes when compared to the fossils of the Pleocene period. Therefore the marsupial's visual system retrieves characteristics from ancient mammal evolution to the retinal patterns found in modern mammals.

Keywords: Color perception; Retina/physiology; Electrophysiology; Electroretinography; Opsin 


\section{REFERÊNCIAS}

1. Ahnelt PK, Hokoc JN, Rohlich P. Photoreceptors in a primitive mammal, the South American opossum, Didelphis marsupialis aurita: characterization with anti-opsin immunolabeling. Vis Neurosci. 1995;12(5):793-804.

2. Young RW. Visual cells. Sci Am. 1970;223(4):80-91.

3. Arrese CA, Hart NS, Thomas N, Beazley LD, Shand J. Trichromacy in Australian marsupials. Curr Biol. 2002;12(8):657-60.

4. Jacobs GH. The distribution and nature of colour vision among the mammals. Biol Rev Camb Philos Soc. 1993;68(3):413-71.

5. Couto CP. Paleontologia brasileira: mamíferos. Rio de Janeiro: Ministério da Educação e Saúde: Instituto Nacional do Livro; 1953. vol XVI. 516p.
6. Hokoc JN, Moraes AM. Beta-like ganglion cells in the South American opossum retina: a Golgi study. J Neurocytol. 1992;21(8):614-22.

7. Bowmaker JK. Visual pigments, oil droplets and photopigments. In: Gouras P, editor. Perception of color. Basingstoke: Macmillan; 1991. p.108-27.

8. Lima SMA. Ontogênese e distribuição de subtipos de fotorreceptores na retina do gambá, Didelphis marsupialis aurita [tese]. Rio de Janeiro: Universidade Federal do Rio de Janeiro, Instituto de Biofísica Carlos Chagas Filho.; 1998.

9. Daw NW, Pearlman AL. Cat color vision: one cone process or several? J Physiol. 1969;201(3):745-64.

10. Bowmaker JK, Dartnall HJ, Lythgoe JN, Mollon JD. The visual pigments of rods and cones in the rhesus monkey, Macaca mulatta. J Physiol. 1978;274:329-48.

11. Neitz J, Neitz M, Jacobs GH. More than three different cone pigments among people with normal color vision. Vision Res. 1993;33(1):117-22. 